\title{
The Learning Potential of Boundary Crossing in the Context of Product Introduction
}

\author{
Maria Gustavsson $^{1}$ (D) Kristina Säfsten ${ }^{2}$
}

Received: 2 May 2016 / Accepted: 22 December 2016 /

Published online: 7 January 2017

C The Author(s) 2017. This article is published with open access at Springerlink.com

\begin{abstract}
The aim is to explore challenges related to the integration between product development and production in product introduction and, given these challenges, to analyse the learning potential of boundary crossing in the context of product introduction. The paper draws on evidence from a Swedish manufacturing company. The theoretical framework is based on a boundary-crossing perspective, which in turn is framed by a workplace learning perspective. Data were collected through interviews with 19 employees from the product development department and 21 employees from the production plant, and 8 focus-group interviews. Within the company, there were many challenges related to product introduction, but the findings also show these challenges can provide learning opportunities by enabling the boundaries to be crossed between the product development department and the production plant. Several forms of intrapersonal or interpersonal boundary crossing were identified. Individuals acted as brokers, and prototypes, pre-series, DfA analysis and a crossfunctional team served as boundary objects and encounters. Nothing in our study indicates that the boundary crossing identified on the intrapersonal and interpersonal levels created learning potentials on the organisational level in the company. The conclusion is that it is necessary to consider the learning potential made available by boundary crossing in order to support learning, and thereby improve the integration between product development and production in product introduction. By seeing and using prototypes and pre-series production as learning opportunities you can create a better preparedness and provide collective access to knowledge required for successful product introduction.
\end{abstract}

Keywords Workplace learning · Boundary crossing · Product development project

Maria Gustavsson

maria.gustavsson@liu.se

1 Department of Behavioural Sciences and Learning, and HELIX Competence Centre, Linköping University, Linköping, Sweden

2 Department of Industrial Engineering and Management, School of Engineering, Jönköping University, Jönköping, Sweden 


\section{Introduction}

This paper focuses on the learning potential of boundary crossing in a manufacturing company's product introduction. Product introduction, sometimes referred to as industrialisation, is an important part of the product development process ${ }^{1}$ and specifically addresses activities associated with the transfer of a product from product development to serial production (Johansen 2005). Previous research on product development has reported on the need for integration between different activities, functions and competencies (Swink 1999; Unger and Eppinger 2009; Wlazlak 2016) to ensure success in terms of fulfilling the product's specification, quality, cost and delivery requirements. Integration, in this context, can be defined as "interaction processes involving information exchange on the one hand and collaboration or cooperation on the other" (Vandevelde et al. 2002 p. 6). Information sharing and collaboration is especially critical for the success of product introduction, as the introduction requires intensive collaboration between product development and production (Vandevelde and Van Dierdonk 2003; Wlazlak 2016). A number of integration mechanisms have been suggested as solutions to manage the integration between product development and production (e.g. Adler 1995; Drejer 2002; Nobelius 2004; Säfsten et al. 2014). These mechanisms can be considered as managerial tools that assist in achieving integration within an organisation, and they focus on areas such as information sharing and the organising of projects in cross-functional teams (Wlazlak 2016). However, as pointed out in earlier research often due to uncertainty, product introduction faces a number of challenges (Säfsten et al. 2014) that are related to lack of information (Galbraith 1974) or knowledge (Tatikonda and Montoya-Weiss 2001). The sources of uncertainty can be found both in the external environment, such as the fluctuating market demand and customers' requirements, but also in the newness and complexity of the process and product technology (Lakemond et al. 2007). To ensure that information about unforeseen changes in the product development project reaches the personnel involved it is important to have open communication channels, and thereby give the production personnel a chance to prepare the production line (Säfsten et al. 2014). Although much attention has been directed towards the positive effects of integration mechanisms on manufacturing performance (Turkulainen 2008) and towards joint communicative and problem-solving connections (Wheelwright and Clark 1994), and although the involvement of different functions in product development projects has increased in the last few decades through various engineering approaches such as integrated product development (Andreasen and Hein 2000) and concurrent engineering (Koufteros et al. 2001), the integration between product development and production still poses a challenge to product introduction.

A challenge commonly faced by project development projects is the organisational and geographical dispersion between product development and production (Terwiesch et al. 2001; Säfsten et al. 2014) resulting in cultural differences and language barriers (Vandevelde and Van Dierdonk 2003). Another challenge is the fundamental differences between product development and production. Product development and

\footnotetext{
${ }^{1}$ The product development process involves all the activities required to make a product available on the market, such as planning, concept development, engineering design, testing and refinement, and production ramp-up (Ulrich and Eppinger 2015).
} 
production are often considered as separate sub-processes that are carried out by different functions, and in different departments or units in a company. Furthermore, product development is often carried out as a project, a temporary organisation, whereas production is a line organisation, which implies that the time frame and goals for the different activities differ. Another difference is that the personnel involved in product development and production respectively often has different backgrounds and competencies (Magnusson et al. 2006). Product development and production can, to use Wenger's (1998) term, be considered as two different communities of practice. Members of a community of practice share a collective activity in which a common interest binds them together through mutual engagement and the sharing of collective recourses such as routines, tools and notions, which also recreate the community of practice (Wenger 1998).

As described above in the last few decades, a vast amount of research has covered the issue of integration between product development and production in product introduction (e.g. Almgren 1999; Swink 1999; Vandevelde et al. 2002), and the issue is still topical (Wlazlak 2016) but so far, little attention has been paid to product introduction from a workplace learning perspective, specifically from a boundarycrossing perspective. Given the above description of product development and production as two different communities of practice, according to Akkerman and Bruining (2016 p. 242) a boundary crossing perspective can provide a more "finegrained" analysis, as it targets the work relationships and learning opportunities of situations in which different communities of practice need to collaborate, such as the context of product introduction.

Departing from a boundary-crossing perspective, the aim of the paper is twofold: 1) to explore challenges related to the integration between product development and production in product introduction and, given these challenges 2) to analyse the learning potential of boundary crossing in the context of product introduction. The paper draws on evidence from research conducted (2007-2011) in a Swedish manufacturing company.

In the following section, the paper starts by outlining the theoretical framework of boundary crossing which is based on a workplace learning perspective, and we also provide some examples of boundary crossing in product introduction. The subsequent two sections provide an overview of the research setting and the methodology. Thereafter, the findings are presented in three sections and discussed. As challenges in product introduction often arise from the integration between product development and production, we initially explore current challenges facing the company's product introduction. Given these challenges, we then deepen the analysis to understand the learning potential of boundary crossing. Finally, some conclusions are presented.

\section{Theoretical Framework}

The theoretical framework is based on a boundary-crossing perspective, which in turn is framed by a workplace learning perspective that has its origins in situated learning theory (Lave and Wenger 1991; Wenger 1998) and activity theory (Engeström et al. 1995; Engeström and Sannino 2010). Both these theories emphasise that there are potentials for learning at boundaries between two or more communities of practice (see 
also Akkerman and Bruining 2016). As argued above, product development and production can be seen as two different communities of practice that are essential for the success of product introductions. Communities of practice are crucial learning environments based on joint activities, mutual engagement as well as the sharing of a collective repertoire including for instance routines, tools etc., which recreate the community of practice (Wenger 1998). Learning is defined as a social process of participation in everyday activities in and between communities of practice (Lave and Wenger 1991; Wenger 1998). As noted by Wenger (1998), communities of practice define and develop boundaries, and sometimes the boundaries need to be crossed, reorganised or even dissolved in order to expand the opportunities for learning. The claim, from a boundary-crossing perspective, is that boundary crossing opens up learning opportunities at boundaries across which individuals and/or groups need to collaborate. Akkerman and Bruining (2016 p. 243; see also Akkerman and Bakker 2011 p. 133) define boundaries as "sociocultural differences between practices leading to discontinuities in actions and interactions". Departing from their multilevel boundary-crossing model, they note that boundaries can be crossed on intrapersonal (i.e. brokers), interpersonal (i.e. between specific groups) and institutional (i.e. multiple organisations or organisational units) levels, separately or simultaneously. Intrapersonal and interpersonal boundary crossing can trigger collaborative learning between individuals and specific groups on the local level, without any boundary crossing taking place at the institutional level. However, boundary crossing on the institutional level is assumed to be preceded by boundaries being crossed on the other two levels.

Crossing boundaries is often challenging because it requires encountering the unfamiliar that is, new learning activities and new ways to collaborate (Engeström et al. 1995; Wenger 1998). According to Engeström et al. (1995), in technological and product innovations interaction across horizontal boundaries is common to support learning and collaboration in terms of providing help, information, and tools to jointly formulate solutions to redesign and produce innovative products (see also Wenger et al. 2002). In product development projects and associated product introductions, individuals are often rewarded for focusing on their own tasks rather than on collaboration. Projects are not always run by the same people and the results rely on the competence of individuals or specific work teams (Bellgran and Säfsten 2010).

Literature on boundary crossing distinguishes diverse ways to cross boundaries and bridge gaps between intersecting communities of practice (Akkerman and Bruining 2016; Akkerman and Bakker 2011; Wenger 1998). According to Wenger (1998), brokers, boundary objects and encounters, as well as cross-sections are common forms through which communities of practice could be bridged. Below, these forms of boundary bridging are described, and some examples related to product introduction are presented.

Brokers are persons who establish linkages across boundaries between communities of practice (Wenger 1998). Brokers can, at first glance, be invisible, but they have central positions at intersecting boundaries between communities of practice, and they are given great responsibility for bridging the boundaries (Akkerman and Bruining 2016). An example related to product introduction is when a cross-functional team, consisting of persons from both product development and production, is set up in the early phases of a product development project. In these phases, engineering methods such as design for manufacturing (DfM) and design for assembly (DfA) are applied in a 
systematic analysis of the product design with respect to manufacturability and assemblability (Boothroyd 2005). The use of engineering methods such as DfM or DfA requires manufacturing or assembly competence to support the early product design phase (Boothroyd 2005; Eskilander 2001; Fabricius 1994). During a DfM/ DfA analysis, a person from the production department may be a broker, since this person's experience of the manufacturing of the product is utilised in the product development. However, there are several ways of performing DfM/DfA. The methods can be based on the engineering designers' personal knowledge, on expert knowledge, design guidelines, specific tools, cross-functional teams, etc. (Herbertsson 1999). A combination of the above-mentioned ways of working with DfM/DfA is often applied, which creates several opportunities for brokering across boundaries.

Another example is technology brokering, which occurs when technological solutions are transferred from one community to another, thereby supporting technological development (Hargadon and Sutton 1997). In such situations, technology brokers can assist by exchanging information and supporting co-workers in finding innovative solutions by recombining old ideas into new solutions. However, maintaining the role of broker and acting competently in unfamiliar situations require, as Walker and Nocon (2007) argue, boundary-crossing competence. Boundary-crossing competence is developed if there are rich opportunities for learning and for horizontal movements between communities of practice (Fuller et al. 2007). The expansiveness of learning environments is dependent on a number of workplace conditions such as technology, division of labour and leadership (Fuller and Unwin 2004) and the accessibility of production procedures and work instructions (Adler and Borys 1996).

Another way to bridge boundaries is by using boundary objects, often artefacts (things, tools), and by using boundary encounters such as meetings, conversations and visits (Wenger 1998). According to Star and Griesemer (1989), boundary objects serve as an interface between communities of practice, and the objects are used in various ways in order to adapt to local needs. Star and Griesemer (1989) also note that it is not necessary for different communities of practice to fully understand the boundary object as it functions as a point of cooperation, communication and negotiation. Conversely, Engeström et al. (1995) state that crossing boundaries is difficult without creating a shared understanding of joint problems and without relying on the use of common artefacts such as routines, procedures and language. As Carlile (2002) argues, in order to be useful boundary objects need certain features such as a shared language, and they must also provide means for learning and facilitate joint knowledge transformation. The need of a boundary object to provide a shared language has also been recognised by Bechky (2003). Bechky claims that engineering drawings of a product can be too abstract and unfamiliar for assemblers, as they lack the competence to understand such drawings. She concludes that the drawings are not useful as boundary objects, as they do not create a common ground of understanding across community boundaries. Negotiation across boundaries can lead to a common understanding of the product, machines and problems faced in everyday work on the production floor (Bechky 2003). However, a common ground does not develop automatically; as several researchers have recognised, it needs to be organised in order to support learning and for joint knowledge sharing (Billett 2001; Ellström 2006; Evans et al. 2006; Gustavsson 2009).

Boundary objects that have proven to be particularly useful for the integration between engineers and assemblers are prototypes (Säfsten et al. 2008; Wheelwright 
and Clark 1994). A prototype serves as a focal encounter for problem-solving, testing, communication, and conflict resolution (Wheelwright and Clark 1994). Prototypes have various purposes during different phases of the product introduction. Early prototypes are used for validation of technological or functional solutions in the product design, whereas later prototypes are used for validation of the product's adaptability within the final production process (Johansen 2005).

A third way of bridging two or more communities of practice is cross-connection, which refers to more long-lasting relations that can become more sustained connections, such as new in-between communities or shared problem spaces (Akkerman and Bakker 2011; Wenger 1998). Confrontations between intersecting communities of practice can start a transformation, which in the long run may lead to identification of shared problem spaces, collaboration and construction of a joint identity (Akkerman and Bakker 2011). Task forces, executive committees and cross-functional teams are examples of connections that can establish continuity in the product introduction (Almgren 1999). Another example is pre-series production, which may function as shared spaces. The purpose of pre-series production is to rehearse volume production, test production systems under serial-like conditions before the start of volume production (Almgren 1999; Clark and Fujimoto 1991) and verify that the developed design, both the product design and manufacturing process design, can be manufactured (Ward and Angus 1996; van der Merwe 2004). Pre-series production is also carried out to familiarise the assembly personnel with the product and the production system (Terwiesch et al. 2001). As mentioned above, the boundaries can be unclear. Sociocultural differences constantly shape the collaboration interface between communities of practice (Akkerman and Bakker 2011) and the respective communities need to accept each other in order to develop crossconnections (Wenger 1998).

\section{Research Setting}

The manufacturing company was part of a research project examining product introduction in the Swedish manufacturing industry. The main reason for the company to participate in the research project was to develop more effective forms of collaboration between product development and production to meet the increasing need for more rapid product start-up. The manufacturing company is part of a larger business group, and is a world-leading supplier of products for industrial and marine applications. With 4000 dealers in 130 countries, the company has a strong global presence, and in 2008 the total number of employees was about 1500. Products were launched in different product segments, and in the study reported on here, the focus was on products for marine applications. In the company, the product introductions were carried out over a limited period of time and required efforts from several functions to fulfil the product's specification, quality and cost requirements. Two units that were separate in terms of location and organisation were selected to participate in the research project: the product development department (PDD) and one production plant (see Fig. 1).

The PDD employed around 20 engineers. The design engineers designed the different engines or parts of engines, the test engineers tested the products under construction, and the project leaders were responsible for the planning, controlling and monitoring product development projects, and consequently for coordinating the product introductions. The 


\section{COMPANY}

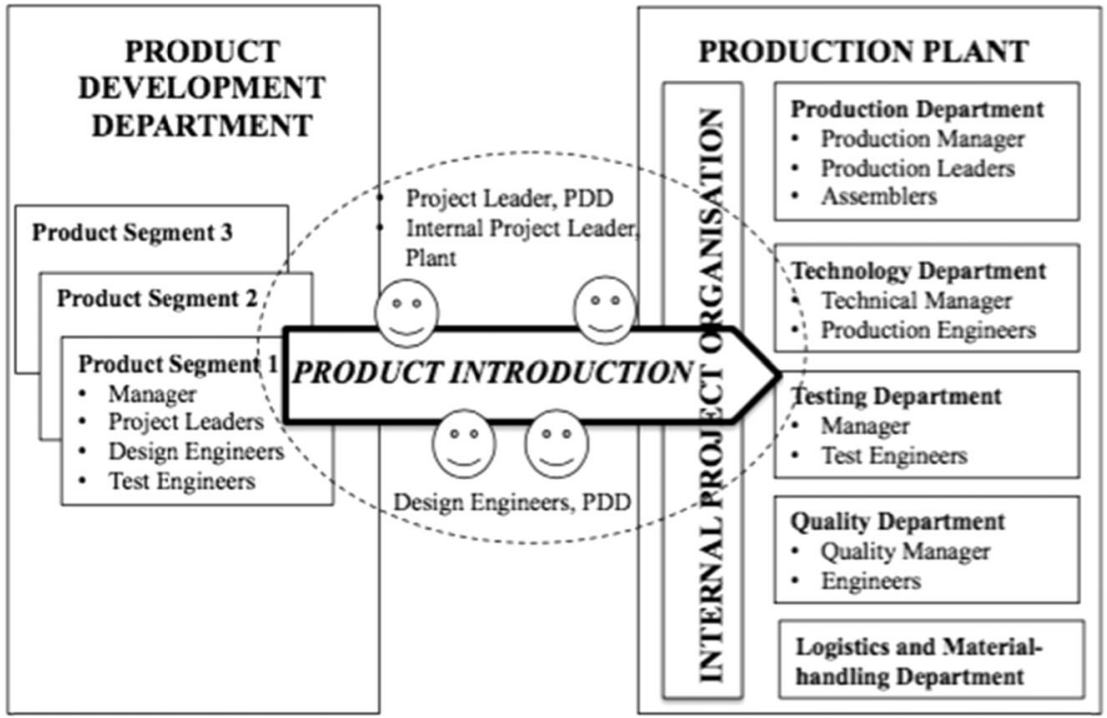

Fig 1 Visualisation of the company's organisation of product introduction and between the product development department (PDD) and the production plant

PDD was organised in groups based on the different product segments, and each group was led by a manager.

The production plant employed around 285 employees but, during the research project it reduced the number of staff to 130 due to a downturn in the production. The plant's line organisation was organised in five departments: the production, technology, testing, quality, and logistics and material-handling department. Each department had an executive manager. In the production department, the production manager had five subordinate production leaders, each responsible for a specific area of the production process, and a number of assemblers. The technical manager and the production engineers in the technology department provided technical support and maintenance. The engineers in the testing department tested prototype materials and engines. The quality manager and engineers in the quality department worked on the quality assurance of products. The logistics and material-handling department supplied the production lines with manufacturing materials.

During product introductions, a temporary internal project organisation was formed separately from the line organisation. The plant's internal project leader (often the same engineer from project to project) was responsible for the dialogue between the production plant and the PDD and monitored the product handover and the preparation for serial production.

\section{Methodology}

The research in the company was conducted in two stages. In the first stage (2008), interviews were undertaken with 19 employees from the PDD and 21 employees from 
the production plant. Almost all employees in the PDD were selected to obtain a wide spectrum of views from the engineers. Two managers, three project leaders, thirteen design engineers and one testing engineer were interviewed. The participants from the production plant were selected strategically to secure a mix of functions that were involved in the company's product introductions. These participants consisted of three managers (the production, quality and technical managers), two production leaders, five production engineers, ten assemblers, and the internal project leader. The purpose of the interviews was to obtain contextual information about product introductions and explore a wide variety of perceptions of challenges related to product introductions. The interviews were semi-structured, and the main themes of the interview guide were product introductions in general, and learning related to product introductions. Each interview was recorded and lasted between one and two hours. The authors of this paper and two other researchers from the research group conducted the interviews at the participants' workplaces. All interviews were transcribed before the analysis. In the initial analysis all transcripts were read for familiarisation and to gain a broader understanding of the product introduction context. In the next step, we carried out a qualitative content analysis of the product introduction which resulted in identification of challenges related to the integration between product development and production, specifically in the process of moving the product from the PDD to the production plant.

The result of the initial analysis, which corresponds to the first aim of our study, was fed back to representatives from both units in a joint workshop arranged by the authors of this paper. In the open discussions with the representatives, it was decided that, to address these challenges related to the integration between product development and production, the authors would continue the research by focusing on bridging boundaries in terms of adaption of new work procedures, inter-collaboration and joint learning between the PDD and the production plant. A joint decision was made to follow a real-time product introduction. A product (an engine) that was going to be handed over from the PDD to the production plant for serial production was selected. This was a unique opportunity for the researchers, and their role was to interactively follow the handover of the product.

In the second stage of the research, focus group interviews were undertaken with eight groups, constituting a mix of occupational categories. The maximum number of participants per interview was four (three on average). The purpose of the focus group interviews was to follow the real-time product introduction over the course of a year (2009-2010). Four employees from the PDD and nine from the production plant participated voluntarily in the focus groups. Eight of the thirteen participants were interviewed more than once, which meant that they chose to participate in two or three focus groups. Eleven of the thirteen participants had also participated in the first stage of the research. The participants, whether they were assemblers, engineers or managers, talked freely about their experiences of the product introduction. During the first two focus group interviews, the conversation was guided by an interview guide, which focused on the product introduction, work procedures, and conditions for collaboration and learning. In the subsequent focus group interviews the questions asked were based on the status of the product introduction, collaboration and learning opportunities. The focus groups lasted between a half hour and two hours and were recorded and transcribed before analysis. To understand the learning potential of boundary crossing in product introduction, the analysis of the interviews was guided by the 
model of multilevel boundary crossing developed by Akkerman and Bruining (2016 p. 246), including forms of boundary bridges between communities of practice such as brokers, boundary objects and encounters, and crossconnections as suggested by Wenger (1998).

\section{Challenges Related to the Integration Between Product Development and Production in Product Introduction}

The main challenge recognised for the integration between the product development and the production was that the PDD and the production plant acted as two different communities of practice (Wenger 1998) whose sociocultural differences led to the development of different routines for product introductions (Akkerman and Bakker 2011). The design engineers perceived that there was a need to develop work methods and routines to improve cooperation between the units. They said that the cooperation with the production plant was particularly important when the schedule was tight and when there were urgent problems to solve. Also, the personnel in the production plant stated that there were no set routines to follow when a problem occurred in a product introduction. As recognised in previous research, it is important that the production personnel be prepared to deal with unforeseen events as high preparedness is seen as a success factor in developing product performance (Kahn 1996; Säfsten et al. 2014).

Both the design engineers and the plant's production personnel perceived difficulties in sharing information. The production personnel said that they suffered from lack of information from the PDD, while the design engineers experienced inadequacies in the communication channels, mainly due to the geographical distance to the production plant, which was a one-hour car ride away. The design engineers said that the communication with the production plant suffered because the production personnel lacked understanding of the engineers' problems.

We don't understand the world of the others (Design engineer, PDD)

Lack of information, knowledge and understanding of each other is a common challenge in product introduction (Galbraith 1974; Tatikonda and Montoya-Weiss 2001). The design engineers often misjudged the time required to manage technical problems with the product design. Sometimes unsolved problems were transferred to the production plant. The design engineers said that before the handover of the product to the plant their task was to solve as many design engineering problems as possible. However, they perceived difficulties in doing their job due to the limited number of tests conducted before moving the product to the production plant and late feedback from the plant on design solutions. On the other hand, respondents from the production plant perceived that when the product design was fixed the design engineers were unwilling to make any changes. There could also be delays in the supply of components for assembly, and some components were not tested to see whether they could be assembled on the production line. The production personnel explained that the design solutions were not always adapted to the production. Late engineering changes in the product design that negatively affected the product's assemblability led to numerous adjustments in the production process. 
Some things could not be assembled. It was not described in the component lists how the fastener would fit into the wiring - there were errors. Since this was impossible to assemble we removed this screw. Oh, I mean we should not have been standing around the engine not knowing this, this was supposed to be clear, bam, bam, bam. It was not that hard because it was a CAD model that they had drawn up. We had to figure out what should be included but it was wrong. It should not have been wrong but it was, and we were unable to assemble it. (Assembler, Production plant)

The design of the product sets limits on how to assemble components (Production engineer, Production plant)

The constant time pressure in the product development projects undermined the integration between the PDD and the production plant. In both the PDD and the plant, there was a high awareness among the staff that there was an unwritten law in the company saying that you must never move forward the start of production since the launch of the product was very seasonally dependent.

Yes, that's the time pressure. There's always too little time when we get involved. The only thing that is certain is that the product launch will take place at a certain time and that time cannot be moved. And then, everything will be compressed as the time required has been misjudged. (Technical manager, Production plant)

Postponing is usually not an option, but it all depends on the difficulty and complexity of the changes we have to make. In some way, one tries to manage the product introduction because it is of great importance /.../ yet more time is spent, costing more money, but we find a solution - and if I don't have the time it takes, I have to reprioritise (Project leader, PDD).

The project leader at the PDD acted as a broker (Wenger 1998). The production personnel said that the project leader's personality had a crucial role in the brokering between the PDD and the production plant. Who was and who was not a good project leader was easily recognised by the production personnel. They described a good project leader as someone who is open and fosters good collaboration by inviting others to jointly discuss issues concerning the product and product introduction.

The product was often transferred to the plant at a late stage. As a consequence, the production personnel felt that they were excluded from the product development project and had little time to prepare for serial production. There was limited time to build and test prototypes in parallel with the production. The pre-series production also had a time limit and it was difficult to prioritise the preparation of the new product during production. The lack of time also created a feeling among the assemblers that their competence was not used and that they had not been given opportunity to familiarise themselves with the new product (Terwiesch et al. 2001). Sometimes, there were conflicts between the product development project and the regular serial production, especially at high production speed. 
If the rates are high and we are working at full speed in the assembly line, there would be a discussion with the production leaders - I mean they want their engines. Day rates and weekly rates, that's what they prioritise. Then you will have to battle a bit against them, if you want project time. (Assembler, Production plant)

In the plant, the perception among the managers, production engineers and assemblers was that no one, except the plant's internal project leader, had a holistic approach to product introduction. The plant's project leader acted as a broker between the plant and the PDD and was given large responsibility for bridging (Akkerman and Bruining 2016) and for representing the plant in the product development projects.

I'm the plant's representative in the projects, meaning I'm the link between the design department and the production /.../ usually I participate, it depends on what phase we're in, but we have meetings either every week, or almost once a week, and we are down there [at the PDD] if it's intense, and if there are minor questions we deal with them on the phone or in a Net-Meeting. (Project leader, Production plant)

Also, the assemblers said that all contacts with the PDD went through the internal project leader. Some of the production engineers and assemblers felt, however, that the project leader failed to keep the people involved in the product introduction properly informed.

The project leader is responsible for the product development project in the plant. /.../ He has too much to do to be able to get the information out to the departments (Production leader, Production plant)

Production engineers and assemblers in the line organisation requested a more frequent dialogue with the internal project leader, especially when there were emerging problems. The assemblers wanted more information concerning what was expected of them well before the start-up of the production. As it was now, problems were solved on an ad hoc basis and the assemblers gained knowledge about the product introduction by learning from mistakes and seeking advice from experienced colleagues.

\section{Boundary Crossing and Joint Learning in Product Introduction}

As the findings shows, the product introduction faced several challenges related to the integration between product development and production in product introduction. The traditional way of connecting the PDD and the production plant was based on brokers and their capability to access and share information (Wenger 1998). The project leaders in the PDD and in the plant, as well as single design engineers were supposed to conduct the technology brokering in order to exchange knowledge (Hargadon and Sutton 1997) between the PDD and the production plant. These brokers were positioned at the intersecting boundary between the PDD and the production plant and were given considerable responsibility for establishing cross-connections (Akkerman and 
Bruining 2016). Intrapersonal connections were developed, each one specific to the broker in the project. These brokers had rich opportunities for crossing boundaries and thereby learning (Fuller et al. 2007), whereas most of the personnel at the production plant were restricted to crossing borders to the PDD.

In the studied product development project, different activities for bridging the boundaries were organised to avoid ad hoc solutions and create arenas for joint learning between the PDD and the production plant. The first joint activity was a DfA analysis carried out under the guidance of a design engineer responsible for the product's reliability. The use of the DfA method opened up for interpersonal boundary crossing (Akkerman and Bruining 2016) between the PDD and the plant.

Then it was this DfA that we were engaged in. We were asked which parts were difficult to assemble on the engine that day. This was almost how it started, we took the engine of the day and went through it and saw the elements that were badly done. (Focus group interview)

This was the first time DfA was used as a tool to jointly discuss the new product and the problems associated with the current product as perceived by the production plant. The overall impression was that the DfA created a good dialogue between the design engineers and the production plant. The assemblers felt that the engineers listened and considered their opinions on assemblability. The design engineers and the production personnel said that the communication between the plant's personnel and the PDD's engineering team was unusually good as they met regularly. It was also easy for them to contact each other to receive answers to questions or just to discuss the product or assembly process. In this situation, the DfA can be considered as a boundary encounter, facilitating boundary crossing on an interpersonal level (Akkerman and Bruining 2016; Wenger 1998).

In the plant, the organisation of product introduction was overhauled in order to connect preparatory activities and encourage joint learning between the plant and the PDD. The production manager was appointed to represent the production plant within the project's steering committee. Thereby, the production manager gained insight into the product development project and could pass on information about the plant's production difficulties to the project management. Moreover, product development issues could be put on the agenda in the plant at quite an early stage. The internal project leadership was divided between two project leaders. One project leader was responsible for the formal contact with the PDD (as before), and the other project leader was responsible for receiving the product and developing a new assembly line.

The new way of organising the product introduction in the plant required development of methods and tools to interconnect the activities of PDD, interactively improving product quality. A cross-functional team, including production engineers, testers, assemblers and material providers was set up to support joint learning in the plant. The cross-functional team supported information sharing (Ulrich and Eppinger 2015) with the PDD and refinements of the product were made continuously during the product introduction. The assemblers said that their early involvement in the product development project through the cross-functional team created a feeling that their competence was better utilised. The creation of new work procedures in the plant supported regular connections between the plant and the PDD that, in turn, supported learning at 
intersecting boundaries (Wenger et al. 2002) and development of boundary-crossing competencies among the production personnel (Walker and Nocon 2007). The crossfunctional team formed an arena in which a common ground legitimated boundary crossing and there was also an acceptance of other's opinions concerning the product introduction (Akkerman and Bakker 2011).

\section{Prototypes and Pre-Series Production - Significant Boundary Objects for Learning}

The most striking finding was that prototypes and pre-series production were significant boundary objects for learning. Early prototypes were built by the design engineers for validation of technological or functional solutions (Johansen 2005) and subsequently, the prototypes were moved to the plant and tested in a separate pilot room. In the studied product development project, the production personnel had access to later prototypes for testing the product's adaptability (Johansen 2005) and solving emerging problems (Wheelwright and Clark 1994). The production personnel said that they thereby learned that it was possible to use the prototypes as an opportunity to joint learning how to assemble the new product.

But now we have perhaps learned a little bit more about what we, from our side, want to get out of the joint building of prototype engines. It is the first project that I have participated in, we just built it - yes they just wanted an engine and then we assembled it the way one does when one assembles, and the goal was to get the engine ready. Perhaps I understand it better now, the reason for building a prototype engine, that one can find out a few things along the way, not only that the engine is to be built, but that you really document it and test different things /... / if it's only to be assembled and sent off, I mean, then you don't learn so much from it, then they might as well do it themselves and when they have perfected it they can come up here and tell us how to do it. I mean, that is the advantage of us doing it here, that you can have an influence on the design. (Focus group interview)

As boundary objects (Star and Griesemer 1989; Wenger 1998), the prototypes functioned as bridges between the PDD and the production plant. The act of gathering around the prototypes, created interpersonal arenas in which new learning opportunities emerged (Akkerman and Bruining 2016) as they met face-to-face to discuss common topics and problems concerning the product and the production system (Säfsten et al. 2008; Terwiesch et al. 2001; van der Merwe 2004). Gathering around the prototypes, also included the development of instructions for assembling the engine. One of the assemblers was allocated time to draw up the instructions with detailed pictures of the prototype and assembly descriptions. A common understanding of the product provided rich opportunities for exchange of knowledge regarding assemblability (Bechky 2003; Carlile 2002; Engeström et al. 1995) as well as significant opportunities for joint learning across the intersecting boundaries (Wenger et al. 2002) between the PDD and the production plant. 
The pre-series production also had a role as a boundary object and supported interpersonal boundary crossing (Akkerman and Bruining 2016). Pre-series production was used for testing the product and the newly built production line. In the pre-series production the design engineers and the production personnel together followed the product on the line throughout the entire production process in the plant. The design engineers said that it was a useful opportunity for them to see how their design functioned. The designs that did not meet the assembly requirements were solved by the design engineers on site, in collaboration with the production personnel. When the serial production commenced, the design engineers and production personnel continued collaborating. The first engine took three days to produce.

We made an engine in three days /... / The first engine was examined thoroughly, structure and all to check that everything was correctly and properly assembled in the right place and that we agreed on this. Yes, and instructions could be added, as we found deviations along the way. (Focus group interview)

Three engineers from the PDD and an equal number of people from the production plant examined the assemblability step by step and prepared the volume production. In case discrepancies were detected during the assembly, the pre-documented instructions were updated. Moreover, problems were solved continuously, which saved a lot of time at the start of the volume production. This was a unique situation in which the assemblers and design engineers could learn from one another by jointly assembling the product on the production line.

\section{Conclusions}

The first aim of this study was to explore challenges related to the integration between product development and production in product introduction. Given these challenges, the second aim was to analyse the learning potential of boundary crossing in the context of product introduction. As for the first aim, the conclusion is that we have found a pattern of challenges similar to that observed by previous research in the last few decades (Kahn 1996; Säfsten et al. 2014; Vandevelde 2002). It was found that several challenges in the product introduction were due to deficiencies concerning information sharing, communication and collaboration between the PDD and the production plant. The design engineers suffered from a lack of understanding of the consequences of their design solutions for the production and had difficulties doing their job due to inadequate communication, the long geographical distance and limited time for product testing. Conversely, the production personnel requested information from the PDD, for instance regarding design errors and fixed design solutions. The time pressure had implications for both the design engineers and the plant's personnel. The work of the design engineers had an impact on the handover of the product. It was difficult for the design engineers to follow the time plan in the product development project due to unforeseen design problems and the complexity of the product (Lakemond et al. 2007; Säfsten et al. 2014). Therefore, the product was often transferred at a late stage, without proper testing and verification, and the technical problems emerging in the PDD were passed over to the production plant, ending up as the production personnel's problems. 
The product introduction was organised in such a way that few within the plant had access to knowledge about the product introduction or were involved in decisions concerning the assemblability. Our evidence confirmed that the PDD and the production plant were, to use Wenger's term, two different communities of practice. It seems as if the sociocultural difference, the engineer culture in the PDD and the production culture in the plant, was preserved in each community of practice (Wenger 1998).

Evidently, there were many challenges related to product introduction within the company, but as the findings also show, these challenges can provide learning opportunities by enabling the boundaries between the PDD and the production plant to be crossed. The analytic model of multilevel boundary crossing developed by Akkerman and Bruining (2016) was used as tool for understanding the learning potential of boundary crossing in product introduction. The notions of brokers, boundary objects and encounters, and cross-connections as different forms for bridging communities of practice as suggested by Wenger (1998) were applied with the same purpose. As the findings demonstrate, intrapersonal boundary crossing was the traditional way of interconnecting the PDD and the production plant. It was evident that most knowledge sharing between the PDD and the plant was carried out through the project leaders and individual design engineers who acted as brokers between these two communities of practice (Akkerman and Bruining 2016; Wenger 1998). The brokers had rich opportunities for learning over the boundaries and gained valuable knowledge early in the product development project.

The learning potential of interpersonal boundary has to do with actions and interactions in activities in which people from two or more communities of practice participate (Akkerman and Bruining 2016 p. 246). It was found that when a different way of connecting the PDD and the production plant was developed, multiple opportunities for learning emerged. The DfA created learning opportunities as the use of the engineering method stimulated joint learning between the personnel from the PDD and the personnel from the production plant. The production personnel's experiences of assemblability were taken into account early in the product development project. Therefore, the assemblability requirements were incorporated into the product development project. An awareness of prototypes and pre-series production as potentials for learning between the design engineers and the personnel from the production plant was shown. These learning situations in turn opened up more opportunities for learning when jointly working to find the right design solutions. The exchange of relevant information and ideas developed an interface between the PDD and the plant, which supported interpersonal learning. The organisation of a cross-functional team in the plant for early involvement in the product development project stimulated learning over boundaries between the plant and the PDD. Acceptance of each other's perspectives and exchange of experiences seemed to create a common ground between the plant and the PDD - a common ground that facilitated the coordination of the product introduction.

In conclusion, several forms of boundary crossing were found in the analysis. Individuals acted as brokers, and prototypes, pre-series production, DfA analysis and a cross-functional team served as boundary objects and encounters. All of the identified forms of boundary crossing emerged on an intrapersonal or interpersonal level. Nothing in our study indicates that the boundary crossing identified on the intrapersonal and interpersonal levels created learning potentials on the organisational level in the company. According to Akkerman and Bruining 2016), boundary crossing on an 
organisational level is preceded by boundary crossing on the other two levels. Most likely, it takes time to cross boundaries over an organisational level, especially if the boundaries have been difficult to cross in the past, as is the case with the boundary between product development and production. However, the result highlights that it is necessary to consider the learning potential made available by boundary crossing in order to support learning, and thereby improve the integration between product development and production in product introduction. How then, can the learning potential of boundary crossing be accessed in the context of product introduction? By seeing and using prototypes, pre-series production and other joint activities as learning opportunities you can create a better preparedness and provide collective access to knowledge required for successful product introduction. However, further studies are required on the learning potential of intrapersonal, interpersonal and organisational boundary crossing in the context of product introduction.

Acknowledgements The project, which in total involves four manufacturing companies actively taking part in the project and giving access to their knowledge and premises, is financially supported by the Swedish Agency for Innovation Systems (VINNOVA). The results presented in this paper are based on a study carried out within two units at one of the participating companies, to whom we owe deep gratitude.

Open Access This article is distributed under the terms of the Creative Commons Attribution 4.0 International License (http://creativecommons.org/licenses/by/4.0/), which permits unrestricted use, distribution, and reproduction in any medium, provided you give appropriate credit to the original author(s) and the source, provide a link to the Creative Commons license, and indicate if changes were made.

\section{References}

Adler, P. (1995). Interdepartmental interdependence and coordination: the case of the design/manufacturing interface. Organization Science, 6(2), 147-167.

Adler, P., \& Borys, B. (1996). Two types of bureaucracy: enabling and coercive. Administrative Science Quarterly, 41, 61-89.

Akkerman, S., \& Bakker, A. (2011). Boundary crossing and boundary objects. Review of Educational Research, 81(2), 132-169.

Akkerman, S., \& Bruining, T. (2016). Multilevel boundary crossing in a professional development school partnership. The Journal of the Learning Sciences, 25(2), 240-284.

Almgren, H. (1999). Pilot production and manufacturing start-up in the automotive industry - principles for improved performance. Gothenburg: Chalmers University of Technology.

Andreasen, M. M., \& Hein, L. (2000). Integrated product development. Copenhagen: Danmarks Tekniske Universitet.

Bechky, B. (2003). Sharing meaning across occupational communities: the transformation of understanding on a production floor. Organization Science, 14(3), 312-330.

Bellgran, M., \& Säfsten, K. (2010). Production development: design and operation of production systems. London: Springer Verlag.

Billett, S. (2001). Learning through work: workplace affordances and individual engagement. Journal of Workplace Learning, 13(5), 209-214.

Boothroyd, G. (2005). Assembly automation and product design (2nd ed.). London/New York: Routledge Taylor and Francis Group.

Carlile, P. R. (2002). A pragmatic view of knowledge and boundaries: boundary objects in new product development. Organization Science, 13(4), 442-455.

Clark, K., \& Fujimoto, T. (1991). Product development performance. Boston: Harvard Business School.

Drejer, A. (2002). Integrating product and technology development. International Journal of Technology Management, 24(2/3), 124-142. 
Ellström, P.-E. (2006). Two logics of learning. In E. Antonacopoulou, P. Jarvis, V. Andersen, B. Elkjaer, \& S. Hoyrup (Eds.), Learning, working and living. Mapping the terrain of working life learning. Hampshire: Palgrave Macmillan.

Engeström, Y., \& Sannino, A. (2010). Studies of expansive learning: foundations, findings and future challenges. Educational Research Review, 5, 1-24.

Engeström, Y., Engeström, R., \& Kärkkäinen, M. (1995). Polycontextuality and boundary crossing in expert cognition: learning and problem solving in complex work activities. Learning and Instruction, 5(4), 319-336.

Eskilander, S. (2001). Design for automatic assembly - a method for product design: DFA 2. Stockholm: Royal Institute of Technology.

Evans, K., Hodkinson, P., Rainbird, H., \& Unwin, L. (2006). Improving workplace learning. London/New York: Routledge Taylor and Francis Group.

Fabricius, F. (1994). Design for manufacture - guide for improving the manufacturability of industrial products. Lyngby: Institute of Product Development.

Fuller, A., \& Unwin, L. (2004). Expansive learning environments: integrating organizational and personal development. In H. Rainbird, A. Fuller, \& A. Munro (Eds.), Workplace learning in context. London/New York: Routledge Taylor and Francis Group.

Fuller, A., Unwin, L., Felstead, A., Jewson, N., \& Konstantinos, K. (2007). Creating and using knowledge: an analysis of the differentiated nature of workplace learning environments. British Educational Research Journal, 33(5), 743-759.

Galbraith, J. R. (1974). Organization design: an information processing view. Interfaces, 4(3), 28-36.

Gustavsson, M. (2009). Facilitating expansive learning in a public sector organization. Studies in Continuing Education, 31(3), 245-259.

Hargadon, A., \& Sutton, R. (1997). Technology brokering and innovation in a product development firm. Administrative Science Quarterly, 42(4), 716-749.

Herbertsson, J. (1999). Enterprise oriented design for manufacturing: on the adaptation and application of DFM in an enterprise. Linköping: Institute of Technology.

Johansen, K. (2005). Collaborative product introduction within extended enterprises. Linköping: Linköping University.

Kahn, K. B. (1996). Interdepartmental integration: a definition with implications for product development performance. Journal of Product Innovation Management, 13(2), 137-151.

Koufteros, X., Vonderembse, M., \& Doll, W. (2001). Concurrent engineering and its consequences. Journal of Operations Management, 19(1), 97-115.

Lakemond, N., Johansson, G., Magnusson, T., \& Säfsten, K. (2007). Interfaces between technology development, product development and production: critical factors and a conceptual model. International Journal of Technology Intelligence and Planning, 3(4), 317-330.

Lave, J., \& Wenger, E. (1991). Situated learning: legitimate peripheral participation. Cambridge: Cambridge University Press.

Magnusson, T., Johansson, G., Säfsten, K. \& Lakemond, N. (2006) Bridging the boundaries between technology development, product development and production, Proceedings of the International Product Development Conference, Milan, Italy.

Nobelius, D. (2004). Linking product development to applied research: transfer experiences from an automotive company. Technovation, 24(4), 321-334.

Säfsten, K., Berglund, M., Gustavsson, M., \& Harlin, U. (2008). Learning and Competence Driven Product Introduction. Proceedings of the 2nd Swedish Production Symposium, Stockholm, Sweden

Säfsten, K., Johansson, G., Lakemond, N., \& Magnusson, T. (2014). Interface challenges and managerial issues in the industrial innovation process. Journal of Manufacturing Technology Management, 25(2), 218-239.

Star, S., \& Griesemer, J. (1989). Institutional ecology, 'translations' and boundary objects: amateurs and professionals in Berkeley's museum of vertebrate zoology, 1907-39. Social Studies of Science, 19(3), $387-420$.

Swink, M. (1999). Threats to new product manufacturability and the effects of development. Team integration processes. Journal of Operations Management, 17(6), 691-709.

Tatikonda, M. V., \& Montoya-Weiss, M. M. (2001). Integrating operations and marketing perspectives of product innovation: the influence of organizational process factors and capabilities on development performance. Management Science, 47(1), 151-172.

Terwiesch, C., Bohn, R. E., \& Chea, K. S. (2001). International product transfer and production ramp-up: a case study from the data storage industry. $R \& D$ Management, 31(4), 435-451. 
Turkulainen, V. (2008). Managing cross-functional interdependencies - the contingent value of integration. Helsinki: Helsinki University of Technology.

Ulrich, K. T., \& Eppinger, S. D. (2015). Product design and development (6th ed.). New York: McGraw-Hill.

Unger, D. W., \& Eppinger, S. D. (2009). Comparing product development processes and managing risk. International Journal of Product Development, 8(4), 382-402.

van der Merwe, E. (2004). A conceptual framework for ramp-up manufacturing. Cambridge: University of Cambridge.

Vandevelde, A., \& Van Dierdonk, R. (2003). Managing the design-manufacturing interface. International Journal of Operations \& Production Management, 23(11), 1326-1348.

Vandevelde, A., Van Dierdonck, R., Clarysse, B., \& Debackere, K. (2002). Is design-manufacturing integration that important? Vlerick Working Papers in Innovation Management, 2002/9. Ghent: Vlerick Leuven Gent Management School.

Walker, D., \& Nocon, H. (2007). Boundary-crossing competence: theoretical considerations and educational design. Mind, Culture, and Activity, 14(3), 178-195.

Ward, T., \& Angus, J. (1996). Electronic product design. London: Chapman and Hall.

Wenger, E. (1998). Communities of practice. Learning, meaning and identity. Cambridge: Cambridge University Press.

Wenger, E., McDermott, R. A., \& Snyder, W. (2002). Cultivating communities of practice: a guide to managing knowledge. Cambridge, MA: Harvard University.

Wheelwright, S., \& Clark, K. (1994). Accelerating the design-build-test cycle for effective product development. International Marketing Review, 11(1), 32-46.

Wlazlak, P. (2016). Integration in global development projects. A study of new product development and production relocation projects. Jönköping: Jönköping University.

Maria Gustavsson has a special research interest in workplace learning, vocational learning, organizational change and development, and workplace health promotion.

Kristina Säfsten has a special research interest in various aspects of the interface between product development and production. She is also interested in research concerning manufacturing strategies, and currently participates in research aiming at supporting appropriate decisions on automation in production systems. 